\title{
Non-Verbal Communication on Campus and Its Cultural Differences
}

\author{
Donghong $\mathrm{Li}^{1}$, Min Yang${ }^{2, *}$ \\ ${ }^{1}$ International College, Northwestern Polytechnical University, Xi'an, 710072, Shaanxi, China \\ ${ }^{2}$ English Language Institute, Xi'an International Studies University, Xi'an, 710128, Shaanxi, China \\ *Corresponding Author. Email: yangmin1979@163.com
}

\begin{abstract}
It's well known that good communication is the foundation of any successful relationship, whether personal or professional. It's important both for teachers and students to recognize that their nonverbal communication is the most powerful. The ability to understand and use nonverbal communication is a powerful tool that can help you connect with others, express what you really mean, and build better relationships on campus.
\end{abstract}

Key Words: Non-verbal Communication; Campus; Cultural Differences

\section{INTRODUCTION}

The definition of non-verbal communication is hard to give due to its complex and multidimensional features. Many scholars propose their own definitions from a different perspective. Samovar, Porter, and Stefani (1998) defined it as "non-verbal communication involves all those non-verbal stimuli in a communication setting that are generated by both the source and his/her use of the environment and that have potential message value for the source or receiver". Some scholars regarded non-verbal communication as "the process by which non-verbal behaviors are used, either singly or in combination with verbal behaviors, in the exchange and interpretation of messages within a given situation or context" (Malandro, L. L. Barker, \& D. A. Barker, 1989, p. 5). Knapp and Hall (1997) defined non-verbal communication as "communication effected by means other than words (assuming words are the verbal element)". This definition is practically useful but it does not adequately account for the complexity of non-verbal communication. Considering all these definitions given above, we can conclude that comparatively speaking, the definition offered by Samovar et al. (1998) is a comprehensive one. It not only marks the boundaries of non-verbal communication but also reflects how the process actually works. This definition involves unintentional as well as intentional behavior in the total communication event, which reveals the nature of non-verbal communication.

Cooper believes that in the school environment, non-verbal communication can play a special auxiliary role in cooperating with language communication in many aspects (Cooper, 1988: 58-60), including:

1) Self-presentation. For example, the teacher stood straight in front of the students, speaking in an instructive tone; the students nodded, took notes, and listened intently.

2) Identification of rules and expectations. The method by which teachers announce rules and regulations is, of course, mainly language, but teachers often adopt non-verbal forms when implementing rules and regulations. For example, teachers use eyes or gestures to stop disciplinary behaviors, eye contact, seating arrangements, body orientation, and facial expressions are all common methods.

3) Feedback and reinforcement. For example, a teacher 's smile, a nod, or a clap on a student 's shoulders can all express praise; conversely, a frown, a doubtful look, or shaking his head indicates "you did something wrong". Teachers can also use smiles, frowns, eyes, and physical touches to express evaluations of students' performance. ${ }^{1}$ 4) Liking and affect. Teachers' "non-verbal behavior can send a signal of showing love to students, and can also show teachers' attitudes to the courses taught, school regulations.

5) Regulation of conversational flow. For example, teachers can use non-verbal signals to specify a certain student to speak, when to speak, the number of times each person speaks, and the length of each speech.

6) Classroom control. For example, teachers can use non-verbal communication behaviors and means to encourage and advocate students' good behaviors and restrain their bad behaviors. To encourage students to actively participate in classroom activities, teachers can let students sit in a semicircle. They can stay for a while after asking questions to students or participating in discussions

\section{TEACHER'S APPEARANCE}

Someone's or something's appearance is the way that they look. While it is common to hear people contemplate about inner beauty being the only thing that counts, research suggests that physical attractiveness plays an influential role in interpersonal encounters. Appearance also affects communication on campus either positively or negatively. 


\subsection{Clothing and Makeup}

As a teacher, it can be tricky picking out clothing that makes you appear professional and approachable to your students. Though many schools have a dress code for students, they do not usually have a clear one for teachers or educators. Clothing and makeup must suit one's identity, personal characteristics, and occasion. This is a characteristic common to all cultures. Teachers are the ones who educate the younger generation and demand more stringently in this regard. On different occasions, each person's dress is different. Teachers are more demanding in schools, especially in the classroom. Avoid wearing elaborate eye makeup when you teach, as it can be distracting for students. A simple, clean look is best. This is also common to all cultures. ${ }^{3}$

In China, "teachers are engineers of human souls, who are responsible for teaching and educating others, and who are exemplary. A teacher's smile, gestures, and hairstyle can all become role models for students." (Mingjian Hao et al., 1991: 157) The basic requirement for teacher appearance should be professional beauty, that is, the clothes and hairstyle must be neat and natural. Clothes must be fit, clean, and neatly buttoned, giving a sense of freshness and elegance. To have an easy manner is not to be overly fashionable when it comes to clothing and hairstyle. Generally speaking, teachers' dress styles should be solemn, lively and natural. Clothes should not be too bright and dazzling but should be elegant, subtle. If a teacher is often dressed up, he will distract students and may become a topic of discussion for some students, affecting the effect of teaching and the teacher's prestige. ${ }^{4}$ Cultural misunderstandings and even cultural errors sometimes occur between Chinese and English teachers on clothing. Some people do not understand cultural differences, and often unconsciously use their cultural practices to measure the dress of others. For example, the Chinese sometimes don't put the shirt in their trousers, and sometimes roll up the shirt with long sleeves when they wear the shirt alone in informal and non-foreign affairs. The Chinese regard this as normal, but the English-speaking countries consider it substandard. Conversely, female teachers in English-speaking countries can wear slippers or clogs to enter classrooms or even formal social occasions, but Chinese people consider them indecent. ${ }^{5}$

\subsection{Behavior and Posture}

Nonverbal behavior includes all communicative acts except speech. Communication means conveying information through signals. We use body language without being aware of it, perceive and interpret other people's body language. A teacher should have a good manner. The general requirement of Chinese teachers' manners and postures is steady and dignified. In public, we should pay more attention to our speech and behavior, especially to avoid the influence of some bad behaviors in society, such as spitting, littering and so on. Teachers are also expected to treat people seriously and gently and behave with humility and confidence. English speaking countries not only pay attention to the stability and elegance of teachers' profession but also pay attention to the attractiveness of teachers' appearance to students.

Not being able to observe physical gestures or facial expressions makes it difficult to understand social nuances. Students must learn appropriate social skills in order to prepare them for success in their homes, their friendships as well as for job and career readiness.

\section{NONVERBAL COMMUNICATION BETWEEN TEACHERS AND STUDENTS IN THE CLASSROOM}

Western scholars believe that the role of non-verbal communication in the classroom is often greater than that of formal teaching itself. Many studies have shown that teachers need to learn to use non-verbal communication to improve the quality of classroom teaching. Cooper said: "Non-verbal communication is very important for teachers. Teachers' non-verbal behavior is related to students' attitudes to school. Studies show that if teachers learn how to use non-verbal communication more effectively in the classroom, teacher and student relations will be improved. Not only that, students "cognitive ability and learning efficiency will also be improved." (Cooper, 1988: 57) Non-verbal communication in the classroom includes classroom environment and the arrangements of desks and chairs, and non-verbal communication behaviors of teachers, nonverbal communication with students.

\subsection{Classroom Environment and Arrangement of Tables and Chairs}

People in both Chinese and English cultures believe that classrooms should be spacious and bright, tables and chairs should be neat and comfortable, and the temperature should be moderate. However, in terms of color, Chinese schools are different from English-speaking countries. Regardless of grade level and student age, white walls are the best. It is believed that this can enhance the brightness of the classroom.

The arrangement of classroom seats reflects the relationship and status differences between teachers and students. The high podium shows the status of teachers, and of course, some factors facilitating teaching. There are three common forms of classroom tables and chairs in English-speaking countries: the traditional arrangement (Table 1), the horseshoe arrangement (Table 2), and the modular arrangement (Table 3) (Cooper, 1988: 62-64). 
Table 1

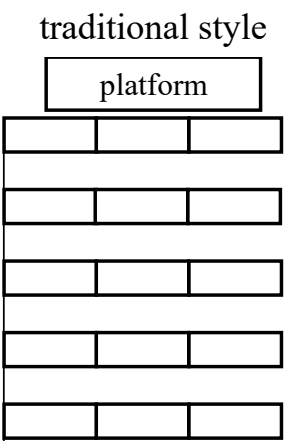

According to the survey, students take the traditional arrangement method when taking compulsory courses, and prefer the horseshoe style and modular style when listening to the elective courses. The traditional style is conducive to communication between teachers and students because teachers can control the entire classroom and it is difficult for students to talk; the horseshoe style is helpful for students to talk; the modular style is good for students to discuss. The choice of the above forms depends on a variety of factors - teaching content, teaching methods, the degree to which teachers want students to participate, and so on. Teachers and students in English-speaking countries feel that the desk arrangements in Chinese schools (as traditional in English-speaking countries) are too monotonous and rigid.

Table 2

horseshoe style

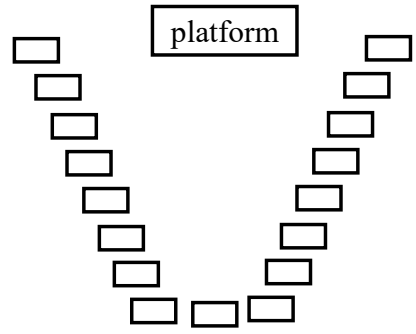

Table 3

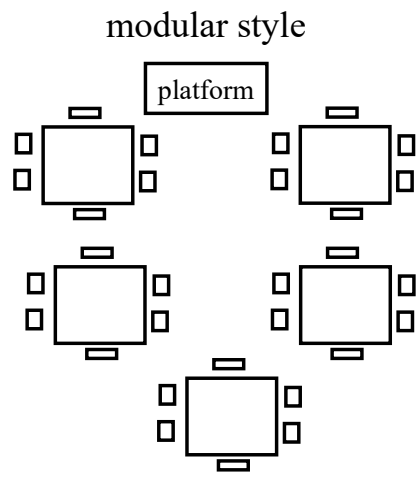

\subsection{Teachers' Nonverbal Communication and Classroom Teaching}

In a sense, the role of nonverbal communication in the classroom is greater than that of formal teaching itself. Teachers' non-verbal communication behaviors can be divided into two categories: non-verbal behaviors that motivate students and non-verbal behaviors that inhibit students' positivity. Many western studies have shown that teachers need to learn to use non-verbal communication behaviors and methods to improve the quality of classroom communication. Cooper said: "It must be remembered that every message contains both content and relationship. Posture, facial expressions, physical behavior, etc., all have an impact on the content of the message. Besides, communication is mainly in non-verbal form. Therefore, students will analyze teachers' non-verbal communicative behaviors to identify teachers' views on teacher-student relationships." (Cooper, 1988: 57)

Chinese teachers regard the classroom as a serious and formal learning environment. Teachers pay attention to their speech and behavior, and students maintain a respectful attitude towards teachers. Teachers in English-speaking countries attach great importance to the active atmosphere of the classroom and do not care much about the behavior of teachers and students. Teachers can sit on the podium, walk around freely, perform exaggerated, and even flick their fingers and put their feet on the chair. Students may say something indecent, but as long as they can play an active role in the classroom atmosphere, teachers do not care.

Chinese teachers are used to walking around the classroom when students' doing their homework or exams, and from time to time they stop and stand next to a student to see how he answers questions. In this regard, students in English-speaking countries are very disgusted, thinking that teachers do not trust them and have been monitoring them. Cooper said: "Body movement can reflect the degree of teachers' trust in students. For example, when you invigilate, you move around in the classroom, see how students answer questions or sit at a table doing your own thing later, but just looking up from time to time? "(Cooper, 1988: 75)

When an elder female teacher in China sees a student dressed thin and seems to have a cold, she shows motherly care, touches the student's clothes, and tells him to wear more. In this regard, students from English-speaking countries are also very disgusted, thinking that the teacher not only violated their territory but also regarded themselves as ignorant children who would not take good care of themselves. Conversely, teachers in English-speaking countries are not very accustomed to the gesture of encouraging or comforting students on the shoulders.

\subsection{Students' Nonverbal Communication and Classroom Teaching}

Chinese and English schools have requirements for students' class discipline and courtesy, but there are also many differences between the two.

In English-speaking schools, teachers do not require students to stand up to pay tribute to the teacher when they enter the classroom. They only ask them to look at the 
teacher to show that they are ready for class. In China, students were required to stand up to pay tribute to their teachers. Nowadays, this etiquette is generally continued only in elementary and middle schools. In the classrooms of English-speaking schools, students sit more casually, and college students can even put their feet on a chair in front; in Chinese universities, this posture is bad behavior that neither respects the teacher nor observe class discipline.

In Chinese schools, if students are late for class, the traditional requirement is to shout "report!". They are waiting outside the door and can get in with the permission of the teacher. However, this requirement now only applies to elementary and middle schools, and college students generally just enter the classroom silently and explain the reason to the teacher after class. Students who are late at English-speaking schools are only polite to enter the classroom quietly. If you have to leave early due to urgent matters, Chinese university students are supposed to ask the teacher for leave. Students in English-speaking countries do not have this habit. They do not ask for leave in advance, they do not say "hello" to the teacher when they leave the classroom, and they do not have to explain to the teacher afterwards.

\section{NONVERBAL COMMUNICATION BETWEEN TEACHERS AND STUDENTS ON CAMPUS}

In English-speaking countries, students have to enter the teacher's office and are accustomed to knocking on the door first, and they can only enter after permission. If the teacher is calling or talking with someone, they must wait outside the door. Chinese schools have similar requirements. However, in China's schools that receive foreign students, an abnormal phenomenon is often seen: When international students come to the teacher's office to find a teacher, they often "walk straight in", regardless of whether the teacher is talking to someone or having a meeting. There are two possible reasons for this "abnormal" phenomenon: first, many Chinese college students are more casual now, giving foreigners the feeling that they don't have to speak rules in China; second, Chinese teachers regard foreign students not only as students, but also as guests. No matter what they are doing or who they are talking with, as long as overseas students come, they immediately stop other things and turn to receive them, giving them the illusion that they can find teachers regardless of time and occasion. When students from English-speaking countries meet with teachers on or off-campus after class, they often ignore them. Chinese teachers have complained a lot and think they are too rude. Because in this case, Chinese students must respectfully say "hello" to the teacher. It should be said that there are cases where people do not understand politeness, and their psychological reasons are worth investigating. Australians generally think that people who don't take the initiative to greet people are not worthy of contact; American students are generally more casual; some British students think: "It's nothing, but you must say 'hello', isn't it neurosis?" So, among them, there are indeed cultural differences. Chinese culture also requires that between the students and the teachers, the former should say "hello" to show respect. Some of the English-speaking people think that the teacher should take the initiative, otherwise it is easy to be rude, because the teacher may think about the problem while walking and not want to be disturbed by others. ${ }^{6}$

In English-speaking countries, students are not allowed to visit the teacher without the initiative of invitation. They can talk about it in the school teacher's office. In China, teachers' homes, especially those on campus, are open to foreign students, and as long as they visit, they will certainly be warmly received by the host. This is a good custom of Chinese hospitality and has been warmly welcomed by foreign students coming to China.

Chinese teachers also have the habit of visiting students in dormitories, especially when new students arrive at school, old students leave school, and students are sick. Teachers often go to dormitories to visit students because of concern or etiquette. Teachers do not go to student dormitories in English-speaking countries, and students generally do not welcome teachers. Therefore, the kind visits of Chinese teachers are not welcomed by students from English-speaking countries. They think that this is interference to their personal lives, and some students think that the teacher is checking and supervising their studies.

In English-speaking countries, "Ms. Priority" is also used between university teachers and students, unless a teacher is very high-ranking or too old. When a male teacher led a class of students to visit a middle school in a British university, there were not enough seats, the male teacher stood with the male students and gave the chair to the female students.

\section{CONCLUSION}

Nonverbal communication behavior may also change as people adapt to new cultural environments. Sometimes they make conscious changes to adapt to the environment. If we understand that nonverbal communication is common in some cultures, then when someone communicates, we are not so uncomfortable. In order to improve the accessibility of our culture, we should be aware of and sensitive to different values, beliefs, attitudes and assumptions, as well as different cultural patterns of behavior. In this way, our non-verbal communication will be more conducive to the exchange of different cultures.

\section{REFERENCES}

[1] Snyder, D., Classroom Management for Student Teachers. Music Educators Journals, pp. 37-40, 1998.

[2] Zhao Biao. Lines and Circles, West and East. English Today, pp. 67, 17 (3): 4, 2001.

[3] Gao Yihong. Understanding and Transcending the Differences Between Language and Culture. Beijing: Foreign Language Teaching and Research Press, 2000.

[4] BI, J. W. Non-verbal communication. In W. Z. HU (Ed.), A Dictionary of British and American Culture. Beijing: Foreign Language Teaching and Research Press, 1995.

[5] Zanger, V. V. Face to Face - the Cross-Cultural Workbook. Newbury House Publishers, 1985.

[6] Tomalin, B. \& S. Stempleski. Cultural Awareness. Shanghai: East China Normal University Press \& Oxford University Press, 1998. 